\section{Stabswechsel bei Berlac}

$M$ it Wirkung zum 1. Januar 2013 übernahm Dr. Dietmar Chmielewski die Geschäftsführung der Berlac AG. Das Unternehmen gehört zur Berlac Gruppe und hat seinen Sitz in Sissach bei Basel. Chmielewski löst damit Willy Scheuchenpflug an der Spitze des Unternehmens ab, der sich künftig auf die Tätigkeit als CEO der Berlac Gruppe fokussieren wird. Chmielewski verfügt über langjährige Erfahrung in verschiedenen leitenden Positionen der Lackindustrie. Der 50-jährige promovierte Chemiker wirkte unter anderem mit bei der Entwicklung von Auto-, Industrielacken und Druckfarben, wobei der spätere Schwerpunkt seiner Arbeit im Vertrieb von Lacken und Rohstoffen lag. Zuletzt war er Geschäftsführer der Caparol Industrial Solutions $\mathrm{GmbH}$.

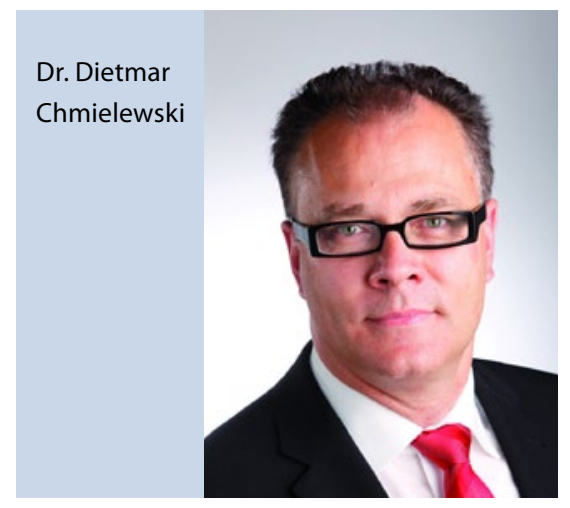

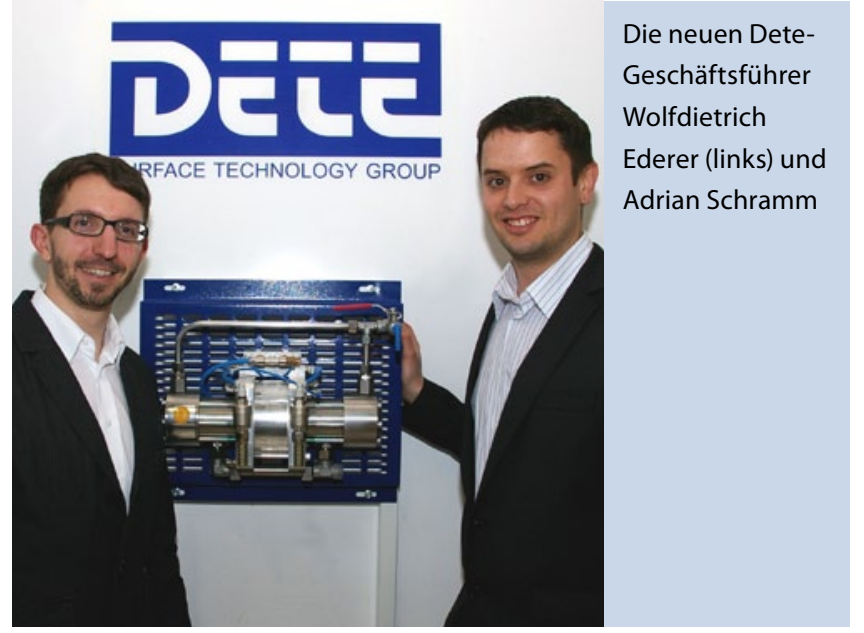

\section{Neue Geschäftsführung bei Dete}

$B^{\mathrm{e}}$ eim Nürnberger Anbieter von Lackieranlagen und Lackiergeräten Dete Dr. Tettenborn GmbH kam es im Zuge des laufenden Generationswechsels zum 1. Januar 2013 zu einer Umstrukturierung der Führungsebene: Adrian Schramm und Wolfdietrich Ederer wurden von der Gesellschaft als neue Geschäftsführer berufen. Sie leiten damit das Unternehmen nach Firmengründer Dr. Hans-Georg Tettenborn, seinem Sohn Hans-Jürgen Tettenborn und den letzten Geschäftsführern Dr. Edit Szabo, Herbert Wiedemann und Jozsef Csanyi bereits in der dritten Generation. Das neue Führungsduo teilt sich die Zuständigkeiten: Schramm fungiert als kaufmännischer, Ederer als technischer Geschäftsführer.

\section{Eisenmann mit neuem Vorstandsmitglied}

$D^{e}$ er Geschäftsführer der Eisenmann Anlagenbau GmbH \& Co. KG, Bruno Geiger (47), ist seit 1. Januar 2013 neues Vorstandsmitglied der Eisenmann AG. Er leitet die Geschäftsbereiche General Finishing, Application \& Robotics und Conveyor Systems. Zudem ist er verantwortlich für die Geschäftsentwicklung der Auslandsstandorte in Indien und Russland. Bruno Geiger verfügt über fun- dierte Branchenkenntnisse und langjährige internationale Erfahrung. Der Diplom-Ingenieur machte berufsbegleitend den MBA an der Steinbeis Hochschule Berlin und war zuletzt Chief Sales Officer bei der Grenzebach Maschinenbau $\mathrm{GmbH}$, einem internationalen Anlagenbauer. Seit März 2012 ist Geiger Geschäftsführer der Eisenmann Anlagenbau GmbH \& Co. KG.

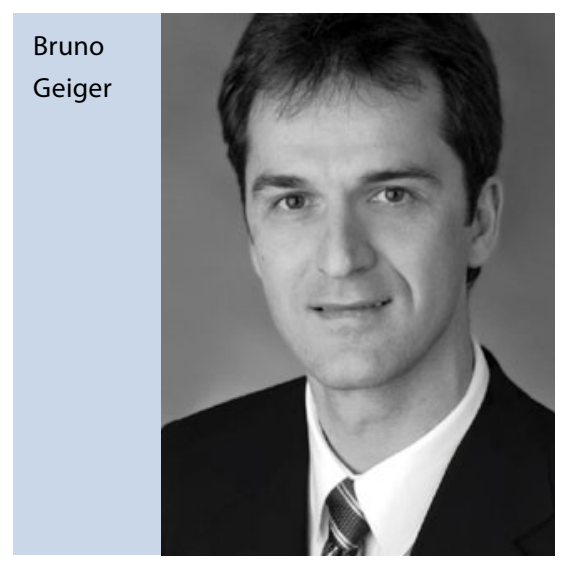

\title{
Checkliste für Auswahl von Reinigungsanlagen
}

Reinigungsanlagen sind oft nicht Redarfsgerecht ausgelegt, woraus ein erhöhter Aufwand oder eine unzureichende Reinigungsqualität resultieren kann. Um Anwender industrieller Reinigungstechnik bei der Auswahl einer geeigneten Reinigungsanlage zu unterstützen, hat der Fachverband industrielle Teilereini- gung (FiT) eine Checkliste erarbeitet. Sie informiert über die Daten, die von Unternehmen bei der Kontaktaufnahme mit einem Anlagenhersteller für ein qualifiziertes Angebot erforderlich sind. Enthalten sind auch Informationen über Prozesse, die beim Anlagen- beziehungsweise Medienhersteller für einen konkreten, auf den
Anwender zugeschnittenen Lösungsvorschlag durchzuführen sind. Eventuell erforderliche Genehmigungen beziehungsweise Anmeldungen bei Behörden werden in der Checkliste ebenfalls thematisiert. Die Checkliste ist im Download-Bereich der Homepage des FiT, www.fit-online.org, kostenfrei abrufbar. 